\title{
Mice expressing the variant rs1143679 allele of ITGAM (CD11b) show impaired DC-mediated T cell proliferation
}

\author{
Justin T. Avery ${ }^{1} \cdot$ Rachel V. Jimenez $^{2} \cdot$ Joseph L. Blake $^{2}$ Tyler T. Wright ${ }^{3} \cdot$ Beatriz León-Ruiz $^{4}$ Trenton R. Schoeb ${ }^{1}$. \\ Alexander J. Szalai ${ }^{2} \cdot$ Daniel C. Bullard ${ }^{1}$ D
}

Received: 13 May 2019 / Accepted: 3 October 2019 / Published online: 31 October 2019

(c) The Author(s) 2019

\begin{abstract}
Genome-wide association studies (GWAS) and functional genomic analyses have implicated several ITGAM (CD11b) singlenucleotide polymorphisms (SNPs) in the development of SLE and other disorders. ITGAM encodes the $\alpha_{\mathrm{M}}$ chain of the $\beta_{2}$ integrin Mac-1, a receptor that plays important roles in myeloid cell functions. The ITGAM SNP rs1143679, which results in an arginine to histidine change at amino acid position 77 of the $\mathrm{CD} 11 \mathrm{~b}$ protein, has been shown to reduce binding to several ligands and to alter Mac-1-mediated cellular response in vitro. Importantly, however, the potential contribution of this SNP variant to the initiation and/or progression of immune and inflammatory processes in vivo remains unexplored. Herein, we describe for the first time the generation and characterization of a mouse line expressing the 77His variant of CD11b. Surprisingly, we found that 77His did not significantly affect Mac-1-mediated leukocyte migration and activation as assessed using thioglycollate-induced peritonitis and LPS/TNF- $\alpha$-induced dermal inflammation models. In contrast, expression of this variant did alter T cell immunity, as evidenced by significantly reduced proliferation of ovalbumin (OVA)-specific transgenic $\mathrm{T}$ cells in 77His mice immunized with OVA. Reduced antigen-specific $\mathrm{T}$ cell proliferation was also observed when either 77His splenic dendritic cells (DCs) or bone marrow-derived DCs were used as antigen-presenting cells (APCs). Although more work is necessary to determine how this alteration might influence the development of SLE or other diseases, these in vivo findings suggest that the $77 \mathrm{His}$ variant of $\mathrm{CD} 11 \mathrm{~b}$ can compromise the ability of DCs to induce antigen-driven T cell proliferation.
\end{abstract}

\section{Introduction}

Mac-1 (ITGAM/ITGB2, CD11b/CD18), a member of the $\beta_{2}$ integrin family of adhesion molecules, is expressed primarily by cells of the myeloid lineage (Tan 2012). ICAM-1,

Alexander J. Szalai and Daniel C. Bullard contributed equally to this work.

Daniel C. Bullard

dcbullard@uab.edu

1 Department of Genetics, University of Alabama at Birmingham, 1700 University Blvd., Birmingham, AL 35294-0013, USA

2 Department of Medicine, University of Alabama at Birmingham, Birmingham, AL, USA

3 Department of Clinical and Health Sciences, University of Alabama at Birmingham, Birmingham, AL, USA

4 Department of Microbiology, University of Alabama at Birmingham, Birmingham, AL, USA
iC3b, RAGE, and CD40L are just a few of its more than 50 biologically important ligands (Rosetti and Mayadas 2016). This adhesion molecule plays an integral role in the recruitment and activation of neutrophils, monocytes, and macrophages during inflammation and participates in phagocytosis and cytokine production (Fagerholm et al. 2013; Herter and Zarbock 2013; Lim and Hotchin 2012). Additional evidence strongly suggests Mac-1 can modulate the immune response, either promoting or inhibiting it depending on the context (Ehirchiou et al. 2007; Han et al. 2010; Ren et al. 2004). For example, engagement of Mac-1 on certain subsets of dendritic cells (DCs) can, depending on the context, either amplify or restrict their ability to stimulate T cell proliferation (Behrens et al. 2007; Chen et al. 2008; Monrad and Kaplan 2007; Sandor et al. 2013; Schmidt et al. 2006; Skoberne et al. 2006; Varga et al. 2007). Thus, while splenic DCs isolated from Itgam null mice (mutants that lack expression of $\mathrm{CD} 11 \mathrm{~b}$ ) showed an impaired ability to promote $\mathrm{T}$ cell proliferation (Ling et al. 2014), bone marrow-derived dendritic cells (BMDCs) from the same mutants had a decreased 
capacity to suppress $\mathrm{T}$ cell proliferation (Bai et al. 2012). Likewise, loss or inhibition of Mac-1 has been reported to protect from or exacerbate inflammation and autoimmunity in different murine models, suggesting a complicated immunoregulatory role for this integrin in disease development (Bullard et al. 2005; Kevil et al. 2004; Leon et al. 2006; Soloviev et al. 2011; Stevanin et al. 2017).

Genome-wide association studies (GWAS) have now linked several ITGAM single-nucleotide polymorphisms (SNPs) with the risk and severity of disorders such as systemic lupus erythematosus (SLE), systemic sclerosis, and melanoma (Anaya et al. 2012; Hom et al. 2008; Lenci et al. 2012; Nath et al. 2008). One of these ITGAM variants, the non-synonymous SNP rs1143679 that results in a $77 \mathrm{Arg} \rightarrow 77 \mathrm{His}$ change in the extracellular domain of human $\mathrm{CD} 11 \mathrm{~b}$, has been shown to modulate certain Mac-1-mediated functions in vitro. For example, cell lines transfected to express human CD11b encoding the 77His variant showed impaired phagocytosis and adhesion and increased IL-6 generation compared to control cells expressing the invariant protein, which has an arginine at position 77 (MacPherson et al. 2011). In addition, primary cells (neutrophils and monocytes) from human donors expressing the 77His ITGAM variant exhibited reduced adhesion to iC $3 \mathrm{~b}$, ICAM1 , and fibrinogen, decreased phagocytosis of opsonized particles, and altered cytokine expression (Fossati-Jimack et al. 2013; Reed et al. 2013; Rhodes et al. 2012; Rosetti et al. 2015; Zhou et al. 2013). Each of these findings has to be interpreted with some caution, however, because (i) in transfected cells expressing ITGAM variants, the function of CD11b ultimately depends on its ability to pair with CD18, whether expressed naturally or after co-transfection with $I T G B 2$; and (ii) in primary cells, the potential impact of other ITGAM SNPs known to be in high linkage disequilibrium (LD) with rs1143679 is not always accounted for. Consequently, it might be that not all of the functional defects so far attributed to the rs1143679 variant are due to 77 His per se. Indeed, our group showed that the SNP rs1143678, resulting in a proline to serine change at amino acid position 1146, compromises neutrophil adhesion and phagocytosis in the absence of the rs 114367977 His variant (Zhou et al. 2013). Lastly, in general, biologically meaningful effects might occur in vivo that might not be detectable in vitro and vice versa.

We took advantage of the high homology between human ITGAM and mouse Itgam to assess the impact of the rs1143679 77His variant on Mac-1-dependent processes in vivo. To accomplish this in complete isolation from other potentially confounding ITGAM variants in $\mathrm{LD}$, we generated by gene targeting in embryonic stem cells mice expressing histidine at amino acid position 77 of the naturally expressed mouse $\mathrm{CD} 11 \mathrm{~b}$ protein. In contrast to prior reports of impaired ligand binding, adhesion, and migration of 77His transfected and primary cells in vitro, we found that compared to wild-type controls, mice expressing 77His showed no statistically significant changes in neutrophil and monocyte recruitment or the extent of tissue damage when subjected to acute inflammation models. However, expression of 77His in mice significantly diminished antigen-specific $\mathrm{T}$ cell proliferative responses. Importantly, this effect on T cells was also observed ex vivo in co-cultures using primary spleen DCs or bone marrow-derived DCs (BMDCs) from 77His mice as APCs. These are the first experiments to address the impact of 77His in vivo and they establish that expression of this variant form of CD11b can impair the ability of DCs to support a full T cell response in mice. Ongoing studies are aimed at identifying the specific Mac-1-dependent processes altered by 77 His that might be responsible for this effect, and determining whether this effect is sufficient to alter the course of $\mathrm{T}$ cell-driven autoimmunity.

\section{Materials and methods}

\section{Structural modeling of the human and murine CD11b proteins}

To obtain evidence that the influence on CD11b of introducing the 77His variant should be comparable in the two species, and to thereby validate our genetic engineering approach, structural models of human and murine CD11b were rendered using the $\mathrm{COACH}$ meta-server for protein-ligand binding site prediction (Yang et al. 2013a, b). The respective invariant (77Arg in human, 77Pro in mouse) and variant (77His) CD11b structures were predicted using the multi-sources threader (MUSTER) algorithm (https:// zhanglab.ccmb.med.umich.edu/MUSTER/) applied to the CD11c template $3 \mathrm{k} 71 \mathrm{G}$ obtained from the protein data bank (PDB) library (https://www.wwpdb.org/). Each structure was then rendered and the invariant and variant versions aligned using the DeepView/Swiss PDBViewer v4.1.0 (https ://spdbv.vital-it.ch/).

\section{Generation of the 77His mouse line}

The Itgam variant mouse line (C57BL/6 J) encoding histidine at amino acid position 77 (77His mice) was generated using an embryonic stem cell gene-targeting strategy as outlined in the Results section. Both conventional sequencing and pyrosequencing of genomic DNA isolated from tail biopsies were used to confirm the presence of the anticipated $\mathrm{C}$ to A nucleotide substitution in exon 3 of the targeted Itgam gene. Pyrosequencing was performed using the following primers: forward-GACAGGTGCCCTCTACCA GTG, reverse-TTGACAAGCCAGGGGTGTTCAC, and sequencing-TGAGACTCACCTTGCAG. To confirm the 
C to A nucleotide exchange in Itgam transcripts, total RNA isolated from the spleens of heterozygous (CA) and homozygous (AA) mice was used as a template for the generation of cDNA (forward primer-TGGTCCAGCTTGGCGGAACC, reverse primer-CCTCTGGGAACTGCTGGGGC), cloned into the TOPOTA cloning vector (ThermoFisher Scientific), and then sequenced.

C57BL/6 J wild-type (WT) and flippase (FLP) mice (B6.129S4-Gt(ROSA)26Sortm1(FLP1)Dym/RainJ) were purchased from The Jackson Laboratory (Bar Harbor, ME). OT-II/CD45.1 mice were generated by crossing OT-II mice (B6.Cg-Tg[TcraTcrb]425Cbn/J) expressing a TCR-specific for ovalbumin (OVA) residues 323-339 [provided by Dr. Francis R. Carbone (Barnden et al. 1998)] with CD45.1 mice expressing the Ptprc ${ }^{\text {a }}$ allele on the C57BL/6 background (B6.SJL-Ptprc ${ }^{a} P e p c^{b} /$ BoyJ; The Jackson Laboratory). Mice containing a CD11b null mutation were generated as previously described (Lu et al. 1997). This mutation was backcrossed for 11 generations onto the C57BL/6 J strain and homozygotes were generated by intercrossing. All animal procedures including euthanasia were approved by The University of Alabama at Birmingham Institutional Animal Care and Use Committee.

\section{Antibodies and flow cytometry}

The following fluorochrome-conjugated anti-mouse antibodies (clones) were used: anti-CD11b (M1/70), -CD11c (N418), -CD45.1 (A20), -CD80 (16-10A1), -CD86 (GL-1), and -CD4 (RM4-5) all from BioLegend (San Diego, CA); anti-GR1 (RB6-8C5), -Ly6C (HK1.4), -CD3e (145-2C11), and -CD28 (37.51) all from eBioscience (San Diego, CA); and anti-MHC-II (M5/114.15.2) from BD Bioscience (San Jose, CA). LIVE/DEAD stain was used to determine the viability of cells and was purchased from Life Technologies (Eugene, OR). Flow cytometry was performed using an LSRII instrument and the acquired data were analyzed using FlowJo software.

\section{Peritonitis model}

Age- and sex-matched 77His and WT mice were injected i.p. with $1 \mathrm{~mL}$ of sterile $4 \%$ thioglycollate (T9032, Sigma Aldridge) or $1 \mathrm{~mL}$ of tissue culture grade PBS as a control. At 4,24 , or $48 \mathrm{~h}$ thereafter, mice were euthanized and $10 \mathrm{~mL}$ PBS was introduced into the peritoneal cavity. The resultant lavage fluid was collected and peritoneal exudate cells were harvested, counted, labeled using anti-CD11b, -Ly6c, and -GR1, and subjected to flow cytometry to enumerate neutrophils (CD11 $\mathrm{b}^{+} / \mathrm{Ly} 6 \mathrm{C}^{+} / \mathrm{GR} 1^{\text {high }}$ cells) and monocytes/

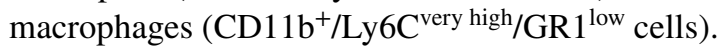

\section{Dermal inflammation model}

The dermal Shwartzman reaction was induced as described previously (Rothstein and Schreiber 1988). Briefly, age- and sex-matched 77His and WT mice received s.c. $100 \mu \mathrm{g}$ of lipopolysaccharide (LPS from Escherichia coli serotype 055:B5; Sigma-Aldrich) in PBS $(100 \mu \mathrm{l})$. Twenty-four hours later (day 1), recombinant TNF- $\alpha(0.3 \mu \mathrm{g} /$ mouse; aa 80-235, R\&D Systems) was injected s.c. at the same site. Control mice received two injections of PBS. Mice were euthanized $24 \mathrm{~h}$ later (day 2) and the skin at the injection site was excised, fixed in buffered $10 \%$ formalin $/ 70 \%$ ethanol, and processed into paraffin. Thin sections $(5 \mu \mathrm{m})$ were prepared and stained with hematoxylin and eosin $(\mathrm{H} \& \mathrm{E})$ for microscopic evaluation, and neutrophilia, hemorrhage, and edema were then scored for their extent and severity in a blinded fashion. For each thin section inspected, the extent of each measure was scored 0 for absent, 1 for $>0-25 \%$, 2 for $25-50 \%, 3$ for $50-75 \%$, and 4 for $75-100 \%$ affected. The severity of each measure was scored 1,2, or 3 for mild, moderate, and severe, respectively, with increments of 0.5 for intermediate degrees (e.g., 2.5 for moderate to severe). The score was calculated as extent $\times$ severity. Scores for each section were averaged. Vasculitis was scored 1, 2, or 3 for mild, moderate, and severe, respectively, with increments of 0.5 for intermediate degrees for each affected vessel. The number of affected vessels having thrombi was counted. The overall score for each mouse was calculated as (neutrophil extent $X$ severity $)+($ hemorrhage extent $X$ severity $)+($ edema extent $X$ severity) + sum of vasculitis scores + count of thrombi. Vasculitis severity also was assessed separately by averaging the individual vasculitis scores for each mouse.

\section{In vivo T cell proliferation}

OT-II/CD45.1 mice were euthanized and their spleens and lymph nodes collected. These were disrupted and after RBC lysis (Sigma-Aldrich, St. Louis, $\mathrm{MO}$ ) $\mathrm{CD}^{+}{ }^{+} \mathrm{T}$ cells were isolated by negative selection using the mouse $\mathrm{CD} 4^{+} \mathrm{T}$ cell isolation kit 19852A (Stemcell Technologies; Seattle, WA) and labeled with Celltrace CFSE (Invitrogen; Eugene, OR). $1 \times 10^{7}$ CFSE-labeled T cells were injected into the tail vein of 77His or WT mice (day 0), and $24 \mathrm{~h}$ later (day 1), each mouse received i.v. $100 \mu \mathrm{g}$ OVA (A-5503; Sigma Aldridge). On day 4, mice were euthanized and their spleens were harvested. Spleen cells were isolated and labeled with anti-CD4 and anti-CD45.1 antibodies, and $\mathrm{CD} 4{ }^{+} \mathrm{CD} 45.1^{+} \mathrm{CFSE}^{+}$ OT-II T cells (events) identified by flow cytometry. To determine the percentage of $\mathrm{T}$ cells present in each proliferating generation, the following equation was used:

$\frac{\text { Events in Generation } \times 2^{\text {Generation Number }}}{\sum \text { Transformed Events }}$ 


\section{In vitro T cell proliferation assays}

Both splenic DCs $\left(\mathrm{CD} 11 \mathrm{c}^{+}\right.$cells) and bone marrow-derived dendritic cells (BMDCs) from 77His and WT mice were used as APCs for in vitro T cell proliferation assays. Splenic DCs were isolated from spleens by positive selection using the EasySep Mouse CD11c ${ }^{+}$Selection Kit II (18780A; Stemcell Technologies, Seattle, WA), and CD4 ${ }^{+}$CD $45.1^{+}$ $\mathrm{CFSE}^{+}$OT-II T cells were isolated as described above. $2 \times 10^{6}$ CFSE-labeled T cells were co-cultured with $4 \times 10^{5}$ DCs (77His, WT, or CD11b-/-) in 96-well round-bottom plates in RPMI complete medium (RPMI 1640, 5\% FBS, 2 mM L-GlutMAX, 50,000 U penicillin/streptomycin, 1\% non-essential amino acids, $50 \mu \mathrm{M} \beta$-mercaptoethanol). Seventy-two or $120 \mathrm{~h}$ after supplementation with $\mathrm{OVA}_{323-339}$ peptide $(1.0 \mu \mathrm{M}$; New England Peptide, Gardner, MA), T cell proliferation (CFSE signal diminution) was assessed by flow cytometry and the percentage of $\mathrm{T}$ cells present in each proliferating generation was then determined using the formula described above for the in vivo $\mathrm{T}$ cell proliferation analyses.

BMDCs were generated as previously described (Jimenez et al. 2018). Briefly, bone marrow was flushed from tibias and femurs of 77His and WT mice and $1 \times 10^{6}$ cells were plated in 12-well flat-bottom plates and cultured in RPMI 1640 media supplemented with 5\% FBS, $2 \mathrm{mM}$ L-GlutaMAX, 50,000 U penicillin/streptomycin, $1 \%$ nonessential amino acids, $50 \mathrm{mM} \beta$-mercaptoethanol, and $20 \mathrm{ng} /$ $\mathrm{mL}$ granulocyte-macrophage colony-stimulating factor (GM-CSF). The medium was changed on days 3 and 5. For antigen-specific $\mathrm{T}$ cell proliferation assays, BMDCs were stimulated/matured with $10 \mu \mathrm{g} / \mathrm{mL}$ LPS in the absence or presence of different concentrations of $\mathrm{OVA}_{323-339}$ peptide $(10,20,40$, and $60 \mathrm{nM})$ on day 6 . On day 7, BMDCs were harvested and used in co-culture assays with $2 \times 10^{5}$ CFSElabeled $\mathrm{CD} 4{ }^{+} \mathrm{CD} 45.1^{+}$OT-II T cells. Cells were cultured at a 1:5 BMDC:T cell ratio in 96-well plates for $72 \mathrm{~h}$, and T cell proliferation was measured by flow cytometry (CFSE diminution).

\section{Analysis of costimulatory markers}

WT and 77His mice were euthanized and their spleens were removed. After RBC lysis, spleen cells were incubated in medium containing RPMI 1640, 5\% FBS, $2 \mathrm{mM}$ L-GlutaMAX, $100 \mu \mathrm{g} / \mathrm{mL}$ pen/strep, $1 X$ non-essential amino acids, and $55 \mu \mathrm{m} \beta$-mercaptoethanol (Fisher Scientific, Lenexa, KS). Cells were then treated with $1 \mu \mathrm{g} / \mathrm{mL}$ LPS or left untreated for $24 \mathrm{~h}$, fixed in $4 \%$ paraformaldehyde, incubated with Fc block (BD Biosciences), and labeled with anti-CD11b, -CD40, -MHC-II, -CD80, -CD86, and -CD11c antibodies, and the expression of these markers were analyzed by flow cytometry.

\section{Statistical analyses}

Where appropriate, the data are presented as means \pm their standard deviations. Differences between genotypes and treatments were assessed using Student's $t$ tests or oneway ANOVA with post hoc Tukey's multiple comparisons tests. Non-parametric measures were assessed using the Mann-Whitney U test. Differences yielding a $p$ value $\leq 0.05$ were considered significant in all statistical analyses, which were performed using GraphPad Prism 7 software (Graphpad, La Jolla, CA).

\section{Results}

\section{A predicted minor effect of the 77His substitution on the structure of human $C D 11 \mathrm{~b}$ is reproduced in the structurally homologous mouse CD11b protein}

Published studies using human leukocytes and transfected cell lines suggest that the 77His ITGAM variant significantly inhibits or alters Mac-1-dependent functions like adhesion, phagocytosis, and cytokine production (FossatiJimack et al. 2013; MacPherson et al. 2011; Maiti et al. 2014; Reed et al. 2013; Rhodes et al. 2012; Rosetti et al. 2012, 2015; Zhou et al. 2013). While these studies have been very informative, they cannot reveal how the 77His variant contributes to authentic immune and inflammatory processes since in vitro and ex vivo systems cannot recapitulate the different tissue microenvironments and biological stimuli encountered by leukocytes in vivo, nor can they effectively model all of the potential cellular interactions, trafficking patterns, and antigens present in the whole organism. To directly address this problem, we took advantage of the high homology between human ITGAM and mouse Itgam and developed a line of mice to investigate the in vivo impact of the rs 1143679 variant allele on Mac-1-dependent responses. We first performed structural analyses to compare the predicted effects of the 77His substitutions on the conformation of the extracellular domain of the human and mouse CD11b proteins. Human ITGAM and mouse Itgam are highly homologous; they share 78.7\% DNA sequence similarity and their encoded proteins have $74.8 \%$ direct amino acid identity. Importantly, this high homology is retained in the region that includes the 77His variant (Fig. 1; compare the sequences shown in panels A and $\left.A^{\prime}\right)$. Protein modeling was used to render a predicted structure of the human and mouse $\mathrm{CD} 11 \mathrm{~b} \beta$-propeller and 
Fig. 1 Amino acid sequences and predicted structures of human and mouse CD11b and their respective 77 His variants. a Amino acid sequence of the region of human $\mathrm{CD} 11 \mathrm{~b}$ adjacent to position 77 (the underlined bold residue). $\mathbf{b}$ The predicted structure of the human CD11b I-domain and $\beta$-propeller regions, with the predicted structures for the common 77Arg (green) and the rs1143679 SNP variant 77His (red) proteins overlaid. $\mathbf{c}$ The boxed area in B is expanded to show the relative positions of the human 77Arg versus 77His residues. $\mathbf{a}^{\prime}-\mathbf{c}^{\prime}$ The wild-type (77Pro; green) versus the engineered (77His; red) versions of the analogous regions of mouse CD11b are shown. In all four situations, residue 77 is in an exposed position on the flank of the $\beta$-barrel, which might allow it to contribute to interactions with Mac-1 ligands. Tertiary structures were predicted with MUSTER using the $3 \mathrm{k} 71 \mathrm{G}$ structure of $\mathrm{CD} 11 \mathrm{c}$ as a template

\section{human CD11b}

mouse CD11b
A ...TGSCEPIRLLQVPVEAVNMSLG...

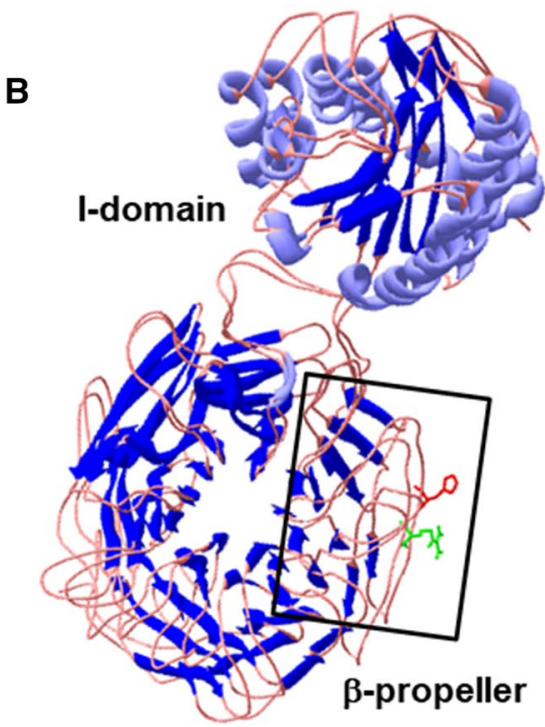

C

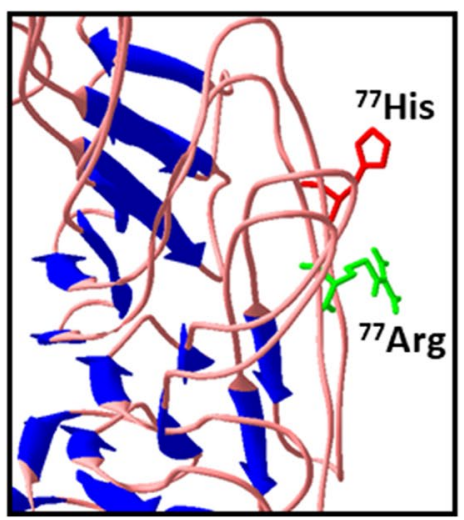

A' $\quad{ }^{70} \quad \stackrel{77}{70} \stackrel{80}{85} \stackrel{95}{90}$

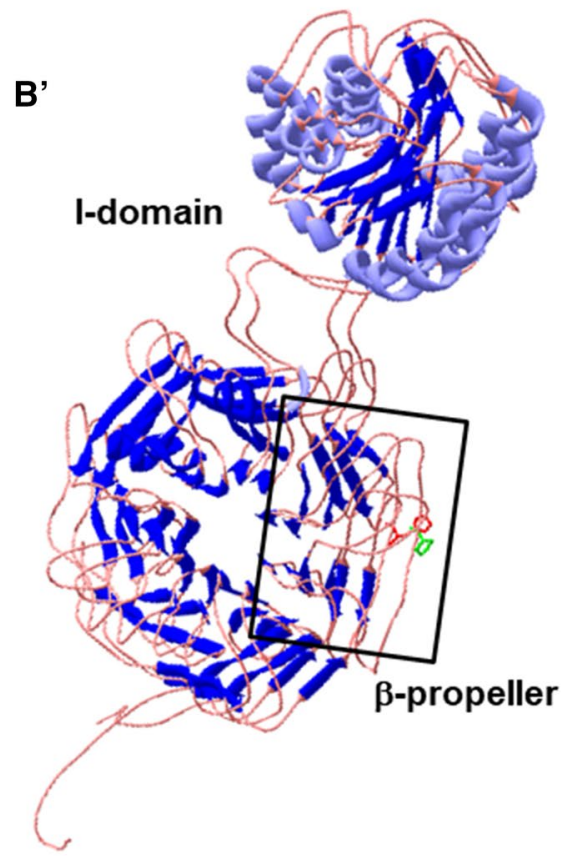

$C^{\prime}$

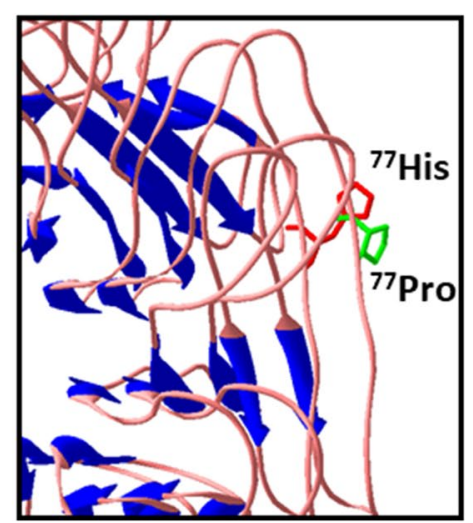

I-domain regions (Fig. $1 \mathrm{~b}$ and $\mathrm{b}^{\prime}$, respectively). Comparison of the predicted structures of the human invariant (77Arg) and variant (77His) proteins revealed only subtle changes (Fig. 1b and c). The predicted structure of the same region in mouse $\mathrm{CD} 11 \mathrm{~b}$ (Fig. $1 \mathrm{~b}^{\prime}$ ) was very similar to that in human $\mathrm{CD} 11 \mathrm{~b}$ and, as for the human variant, introduction of a histidine at position 77 caused only subtle changes in mouse CD11b (Fig. 1c'). In all four situations, residue 77 is in an exposed position on the flank of the $\beta$-barrel, which might allow it to contribute to interactions with Mac-1 ligands.

\section{Generation of the 77His mouse line}

Our structural modeling suggested that the single 77 Pro $\rightarrow 77$ His substitution in the mouse $\mathrm{CD} 11 \mathrm{~b}$ protein should not lead to any major tertiary structural changes that could potentially render Mac-1 incapable of interacting with its natural ligands. Accordingly, by gene targeting in embryonic stem cells, we generated mice expressing histidine at amino acid position 77 of the naturally expressed mouse CD11b. This strategy has the added advantage of allowing us to study the impact of $77 \mathrm{His}$ in complete isolation from other potentially confounding ITGAM variants known to be in high LD. We designed a replacement construct (Fig. 2a) to change the proline expressed at position 77 
Fig. 2 Generation of the 77His variant C57BL/6 mouse. a The wild-type Itgam allele was targeted using a replacement construct that included LoxP sites to flank exon 3 (E3), wherein the 77 His variant is encoded. The neomycin selection gene (NEO; located between E3 and E4 and flanked by FRT recognition sites) was removed by breeding founder mice to $F L P$ recombinase-expressing mice. This yields the 77His Itgam allele. b DNA sequencing trace for a WT cDNA clone derived from the spleen of a 77His heterozygous mouse; note that Pro is encoded at position 77. c DNA sequencing trace for a variant cDNA clone derived from the spleen of a $77 \mathrm{His}$ homozygous mouse; note that His is encoded at position 77
A Itgam allele

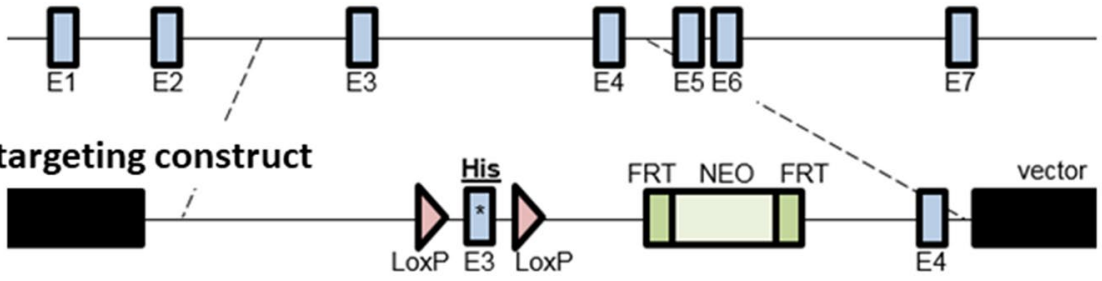

targeted Itgam allele
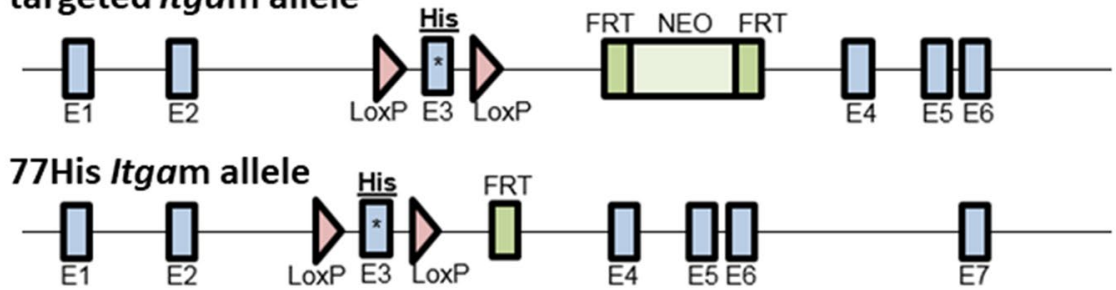

B
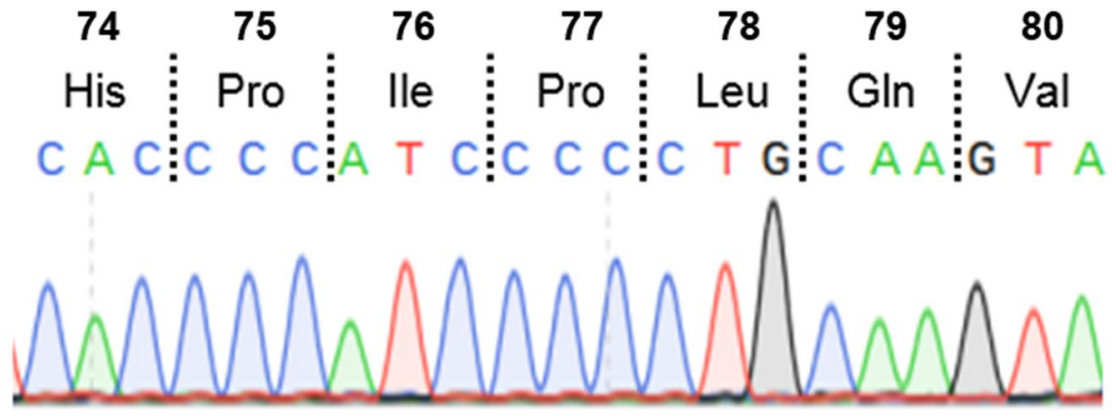

C

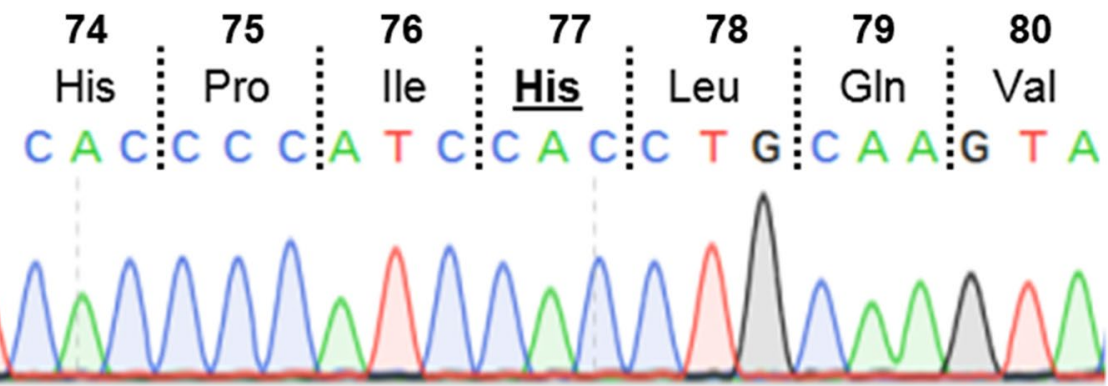

in WT CD11b to a histidine, thereby mimicking the human rs1 143679 SNP variant. In addition to the intended sequence change, the targeting construct included (i) flanking FLP recombinase recognition target $(F R T)$ sites for subsequent removal of the neomycin selection gene and (ii) LoxP sites to generate a conditional Itgam allele for future studies. The targeting construct was introduced into C57BL/6 ES cells by electroporation, and correctly targeted clones (identified by PCR) were injected into blastocysts. After confirmation of germline transmission, mice with the correct nucleotide substitution (i.e., $\mathrm{C}$ to $\mathrm{A}$ in codon 77 of the mature $\mathrm{CD} 11 \mathrm{~b}$ protein; see Fig. 2c) were identified by genomic sequencing of the exon 3 region. Heterozygotes were then crossed to mice expressing FLP recombinase. Their resulting $77 \mathrm{His}$ progeny, lacking the neomycin gene, were intercrossed to generate 77His homozygotes. We confirmed that the $\mathrm{C}$ to A nucleotide substitution was transcribed with high fidelity by sequencing cDNA clones generated from splenic mRNA of 77His heterozygous and homozygous mice (Fig. $2 \mathrm{~b}$ and c, respectively), and we verified that Mac-1 expression on peripheral blood leukocytes and spleen cells from $77 \mathrm{His}$ mice was comparable to those from WT (Fig. 3a and b, respectively). To date, there has been no evidence of embryonic lethality or obvious visible phenotypes observed in the 77 His mice. 
blood
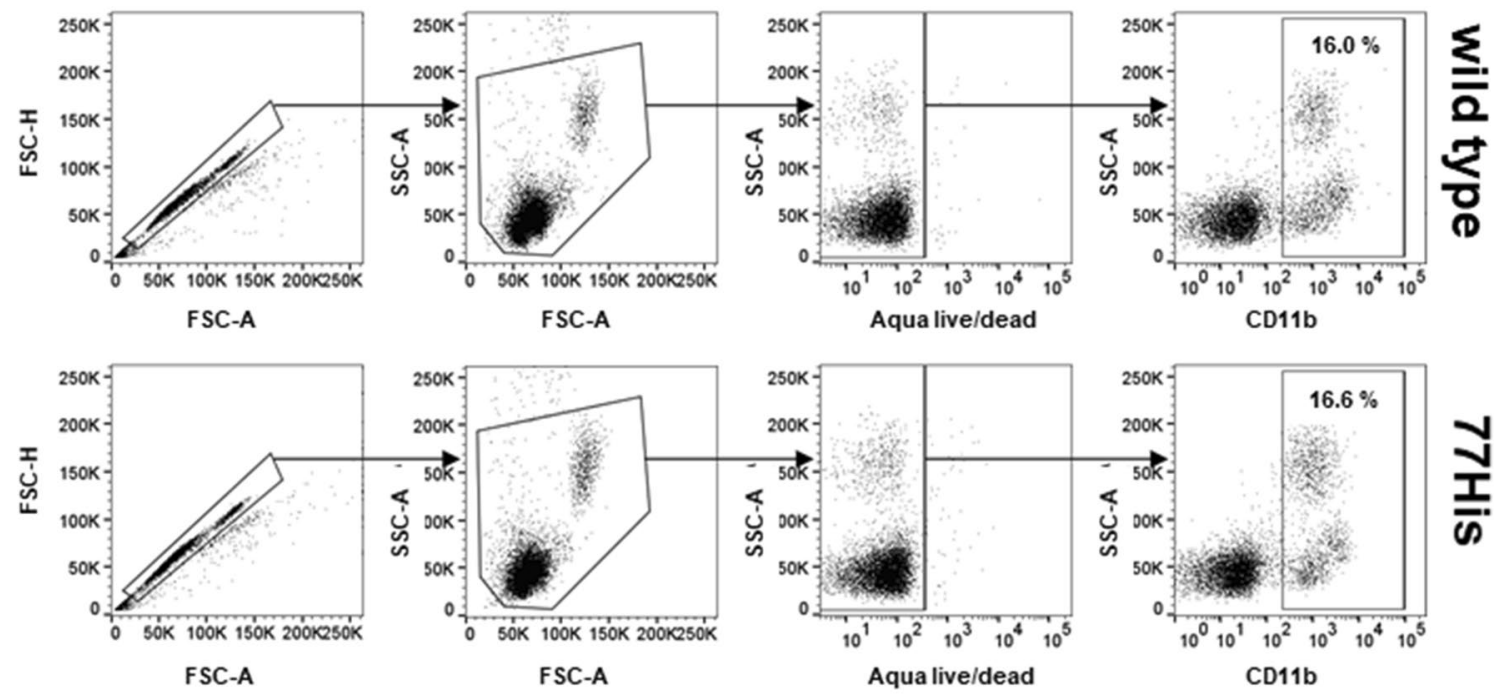

B spleen
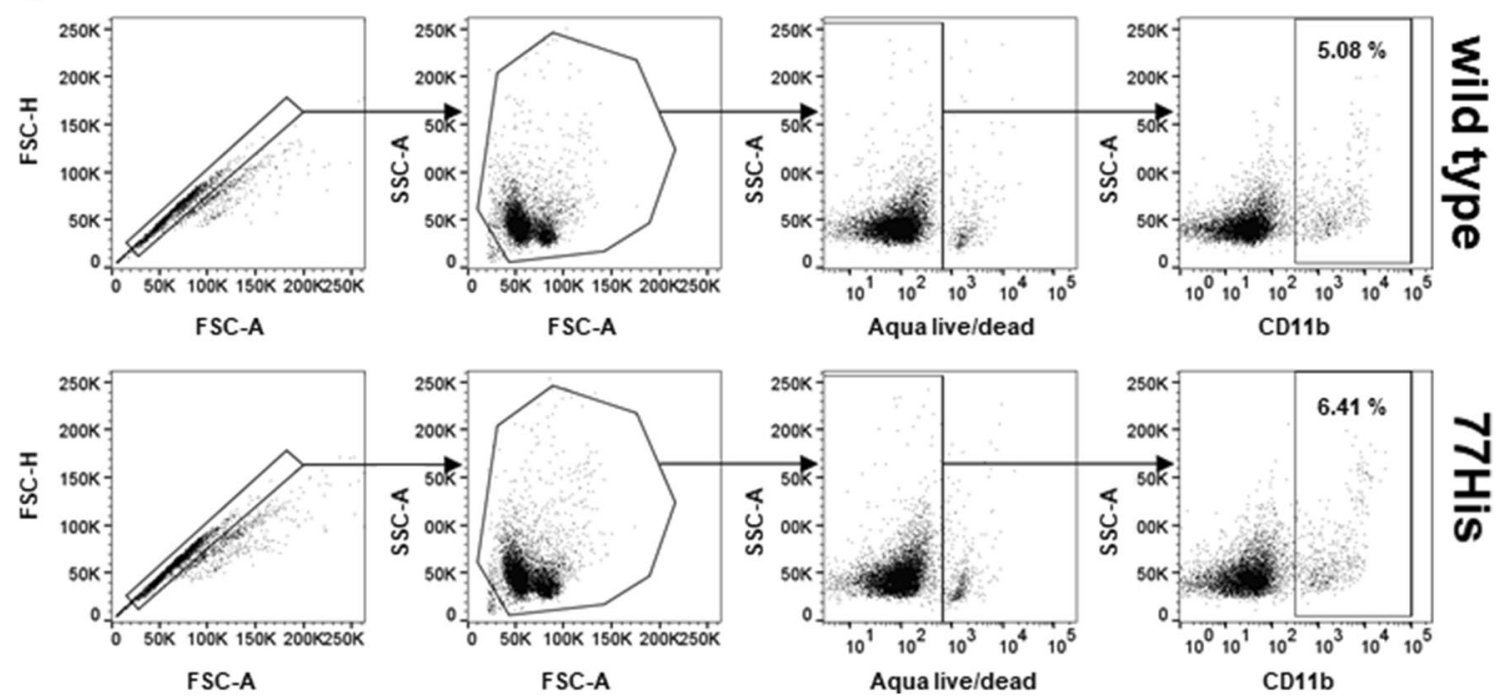

Fig. 3 Mac-1 expression by circulating and tissue resident myeloid cells in WT and 77His mice. Mac-1 expression was analyzed by flow cytometry of peripheral blood cells (a) and spleen cells (b) obtained from 77His and WT mice. In each instance, single cells were identified by FSC-A vs FSC-H, and cells of interest were gated by FSC-A

\section{His does not affect myeloid cell recruitment during localized inflammation}

The importance of Mac-1 in the recruitment of neutrophils and monocytes to sites of inflammation has been well established (Coxon et al. 1996; Dirk Nolte et al. 1994; Jawhara et al. 2017; Mulligan et al. 1998; Tomasz Liberek et al. 2004), and ex vivo studies using human neutrophils and monocytes expressing 77His showed impairment of vs SSC-A, and live cells (aqua Live/Dead negative) were analyzed. There was no difference in the proportion of CD11b cells detected (percentages shown) or the level of CD11b expression (not shown) between genotypes

Mac-1 binding to ligands such as ICAM-1 (Rhodes et al. 2012; Rosetti et al. 2015; Zhou et al. 2013). To determine whether recruitment of neutrophils and monocytes in vivo was affected by $77 \mathrm{His}$, we subjected mice to two different models of sterile localized inflammation. First, we induced peritonitis by injecting thioglycollate. Leukocytes were isolated from the peritoneum of 77His and WT mice by lavage at 4,24 , and $48 \mathrm{~h}$, stained with antibodies for CD11b, Ly6c, and GR1, and neutrophils and monocytes 
enumerated by flow cytometry as shown in Fig. 4a. 77His and WT mice were also injected with PBS as a control, which did not promote leukocyte recruitment into the peritoneal cavity at any of these time points (data not shown). We observed no significant differences in either the concentration or the frequency of either cell type recruited to the body cavity in 77His versus WT mice (Fig. 4b and c, respectively). We next compared the responses of 77 His versus WT mice subjected to the Shwartzman reaction model of localized skin inflammation (Rothstein and Schreiber 1988). In this model, injection of LPS and TNF- $\alpha$ upregulates ICAM- 1 and activates complement, thereby generating the Mac- 1 ligand $\mathrm{iC} 3 \mathrm{~b}$ which, together with cytokine/chemokine production, promotes neutrophil recruitment to the site of injection. The recruited neutrophils subsequently degranulate, leading to fibrin deposition and hemorrhage (Hirahashi et al. 2006). Accordingly, $24 \mathrm{~h}$ after induction of the Shwartzman reaction, skin samples (Fig. 5a) were collected and neutrophil infiltration, fibrin deposition, hemorrhage/edema, and vasculitis were assessed. Although there was a distinct trend towards diminished overall scores for the Shwartzman reaction in 77His mice compared to WT (Fig. 5b), neither this difference nor the differences in each component of the overall score achieved statistical significance. The results of the two studies indicate that the 77 His variant has little or

A
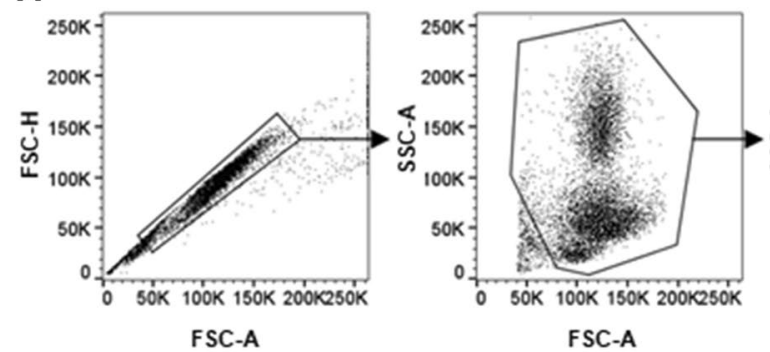

B
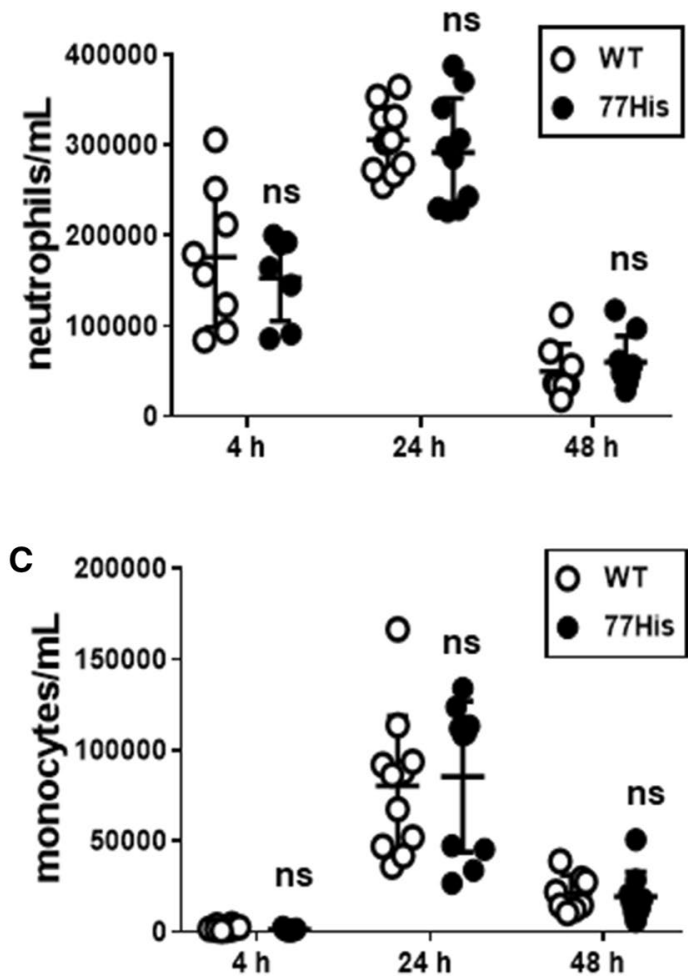
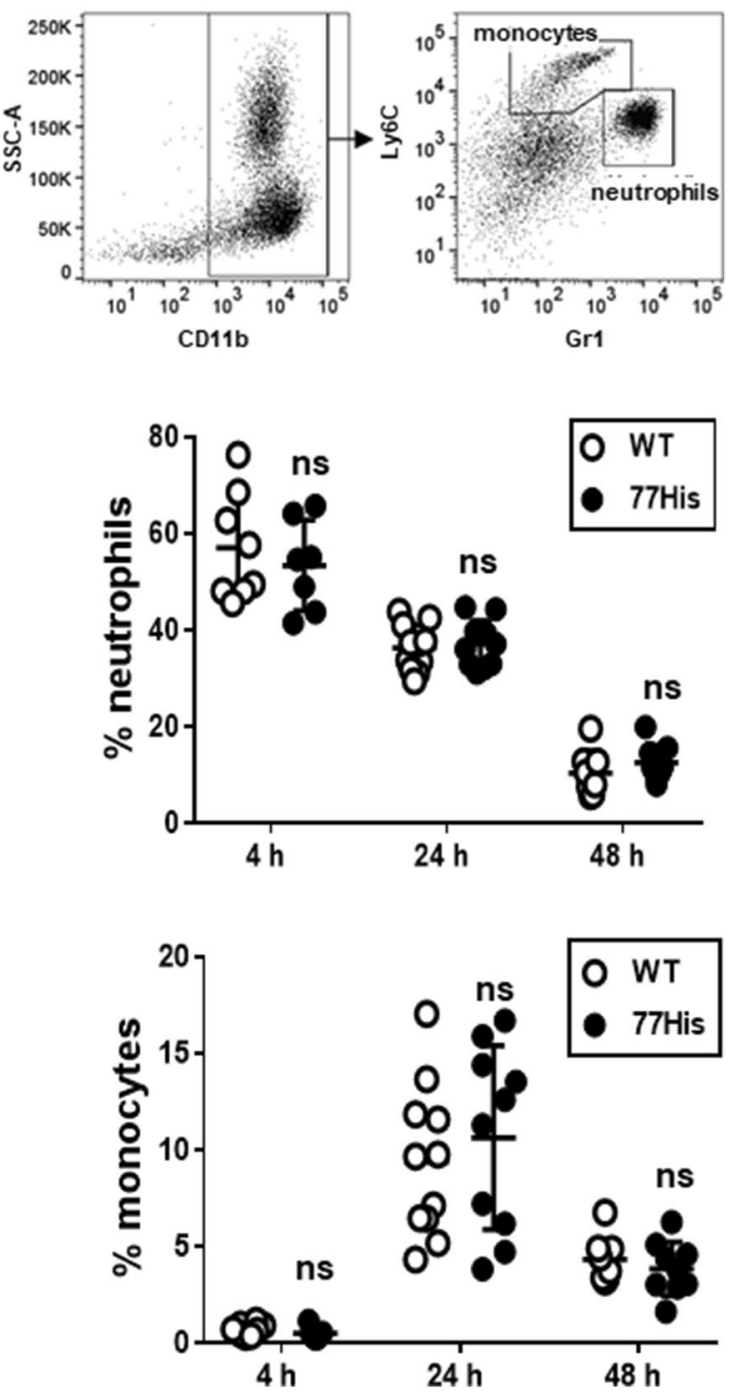

cytometry. The infiltration of the peritoneal cavity by neutrophils (b) and monocytes (c) was unaffected by $77 \mathrm{His}$. The data shown are the mean \pm standard deviation for $N=7-11$ mice per time point per genotype. 'ns' indicates not significant $(p>0.05)$ for $t$ tests comparing 77His to time-matched WT 


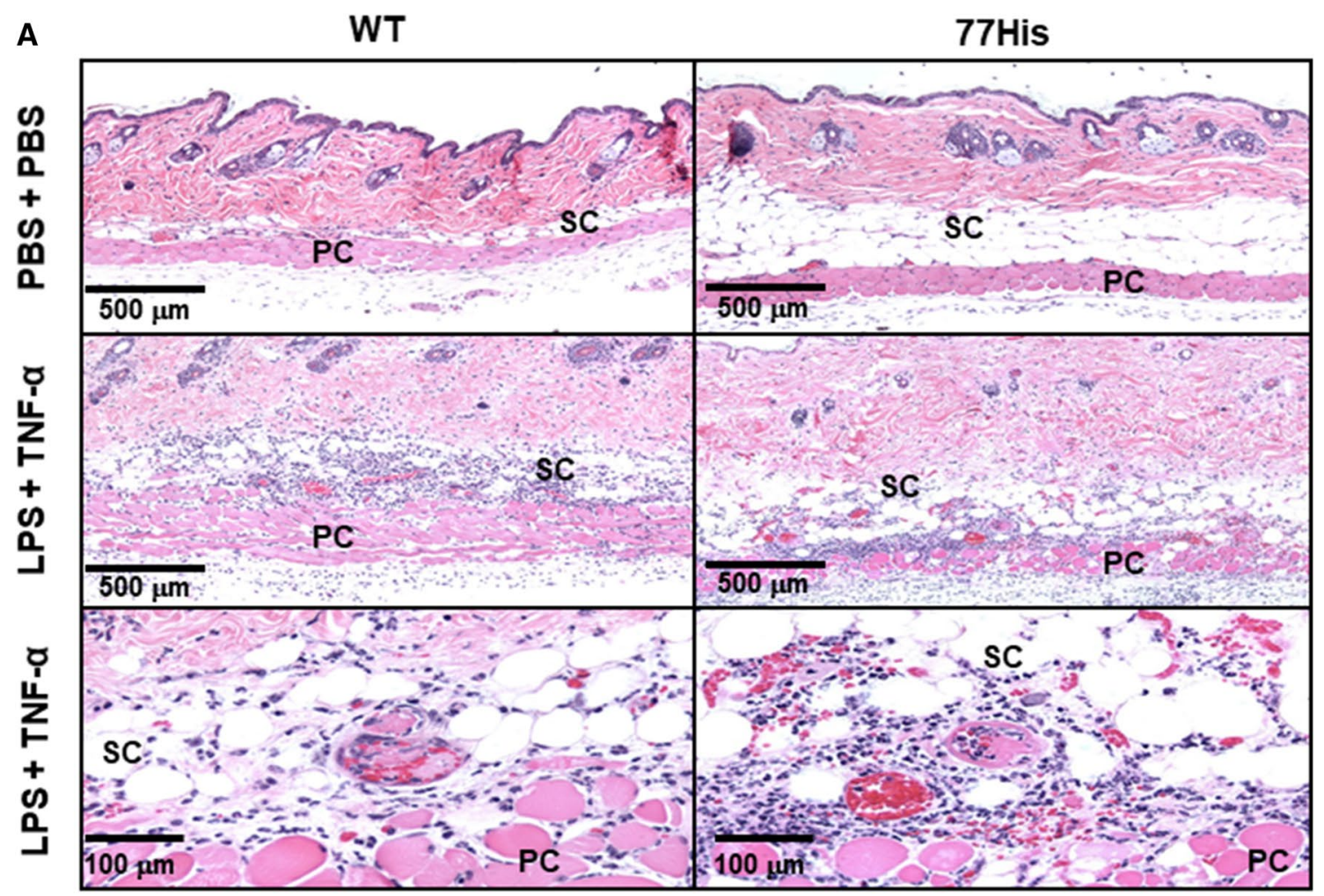

B
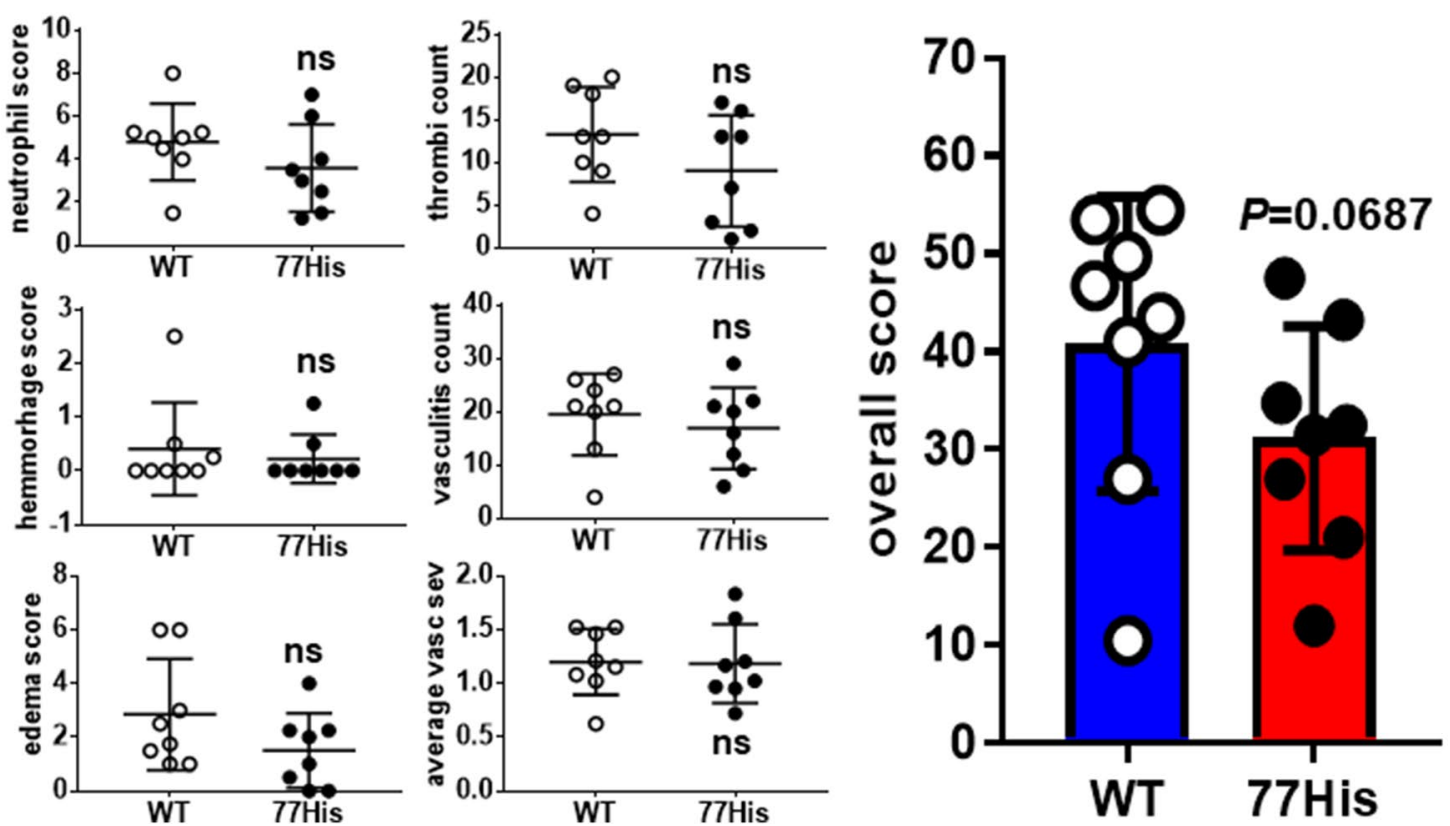

Fig. 5 Marginal effect of the 77His variant in the dermal Shwartzman reaction. a Mice were injected sequentially with LPS and ( $24 \mathrm{~h}$ later) TNF- $\alpha$ as described in the "Methods"; controls were twice injected with PBS. Twenty-four hours after the last injection, skin biopsies were collected, processed, and stained with $H \& E$ for assessment of tissue pathology. Representative thin sections ( $5 \mu \mathrm{m}$ thick) from WT (left panels) and 77His mice (right panels) are shown. In LPS + TNF$\alpha$-treated mice of both genotypes, significant neutrophil recruitment in the subcutis (SC) and panniculus muscle (PC) was observed, as well as extensive vasculitis and thrombosis. b Scores for each individual component of dermal inflammation assessed (see "Methods") were not significantly different (ns) between 77His versus WT mice. The overall score for dermal inflammatory changes was reduced in 77His compared to wild type, but this difference also did not achieve statistical significance (the $p$ value for a Mann-Whitney test is given). The mean \pm standard deviation is shown for $N=8$ mice per genotype 
Fig. 6 77His compromises antigen-driven $\mathrm{T}$ cell proliferation in vivo in mice and in vitro in splenic DC/T cell cultures. a WT and 77His mice received i.v. $1 \times 10^{7}$ CFSE-labeled $\mathrm{CD}^{+} \mathrm{CD} 45.1^{+}$OT-II T cells, followed $24 \mathrm{~h}$ later by $100 \mu \mathrm{g}$ OVA (i.v.). After $72 \mathrm{~h}$, spleens were harvested and flow cytometry used to assess the proliferation of donor $\mathrm{CFSE}^{+} \mathrm{T}$ cells. $\mathrm{T}$ cell proliferation was reduced in $77 \mathrm{His}$ recipients, as indicated by a significant decrease in the percentage of $\mathrm{T}$ cells reaching generation 5. $N=3$ mice per genotype. Non-parametric Mann-Whitney $U$ test; $p<0.05(*)$. b Dendritic cells were isolated from the spleens of 77His and WT mice (see "Methods") and used as APCs for CFSE-labeled CD4 ${ }^{+} \mathrm{CD} 45.1^{+}$OT-II T cells. Co-cultures were provided with $1.0 \mu \mathrm{M} \mathrm{OVA}_{323-339}$ peptide and $\mathrm{T}$ cell proliferation was assessed by flow cytometry after $120 \mathrm{~h}$. T cell proliferation was reduced in co-cultures using 77His DCs compared to WT DCs at generation 6. The data shown are from a single in vitro trial, run in triplicate. Differences between genotypes were assessed using the non-parametric Mann-Whitney $U$ test. Asterisks indicate $p<0.05$ (*). c Dendritic cells were isolated from the spleens of $77 \mathrm{His}$ and WT mice and used as APCs for CFSE-labeled CD4 ${ }^{+} \mathrm{CD} 45.1^{+}$OT-II $\mathrm{T}$ cells as described for panel $\mathbf{b}$, but $\mathrm{T}$ cell proliferation was assessed by flow cytometry after $72 \mathrm{~h}$. T cell proliferation was reduced in cocultures using 77 His DCs, as indicated by a significant decrease in the proportion of $\mathrm{T}$ cells reaching generation 4 . Similar results were observed across 3 separate experiments $(N=3$ mice per genotype for each experiment). Non-parametric Mann-Whitney $U$ test; asterisks indicate $p<0.05(*) . N s$ not significant $(p>0.05)$

no impact on leukocyte recruitment after thioglycollate or LPS/TNF- $\alpha$ induced inflammation.

\section{Dendritic cell function is impaired in 77His mice}

Previous studies suggest an important role of Mac-1 in modulating the ability of DCs to promote/regulate $\mathrm{T}$ cell responses (Behrens et al. 2007; Chen et al. 2008; Monrad and Kaplan 2007; Sandor et al. 2013; Schmidt et al. 2006; Skoberne et al. 2006; Varga et al. 2007). To assess whether the 77His variant had any effect on antigen-specific $\mathrm{T}$ cell proliferation in vivo, $1 \times 10^{7} \mathrm{CFSE}-$ labeled $\mathrm{CD} 4{ }^{+} \mathrm{CD} 45.1^{+} \mathrm{CFSE}^{+}$OT-II T cells (donor cells) were administered i.v. to 77His and WT recipients. Twenty-four hours later, each mouse received i.v. $100 \mu \mathrm{g}$ of OVA. After $72 \mathrm{~h}$ to allow for processing of OVA by recipient APCs and its presentation to donor OT-II T cells, spleens were harvested and the proliferation of the donor $\mathrm{T}$ cells was assessed. We reproducibly observed that OT-II T cells recovered from the spleens of 77His mice showed significantly reduced proliferation compared to OT-II T cells isolated from WT spleens (Fig. 6a). This effect was evidenced by a significant decrease in the percentage of OT-II T cells that had undergone five cell divisions in 77His compared to WT recipients. This result suggests that in vivo the single $77 \mathrm{His}$ change in $\mathrm{CD} 11 \mathrm{~b}$ is sufficient to compromise the ability of endogenous APCs to induce antigen-dependent proliferation of administered $\mathrm{T}$ cells.

To determine whether the observed reduction in donor $\mathrm{T}$ cell proliferation might be due to an effect of 77 His on
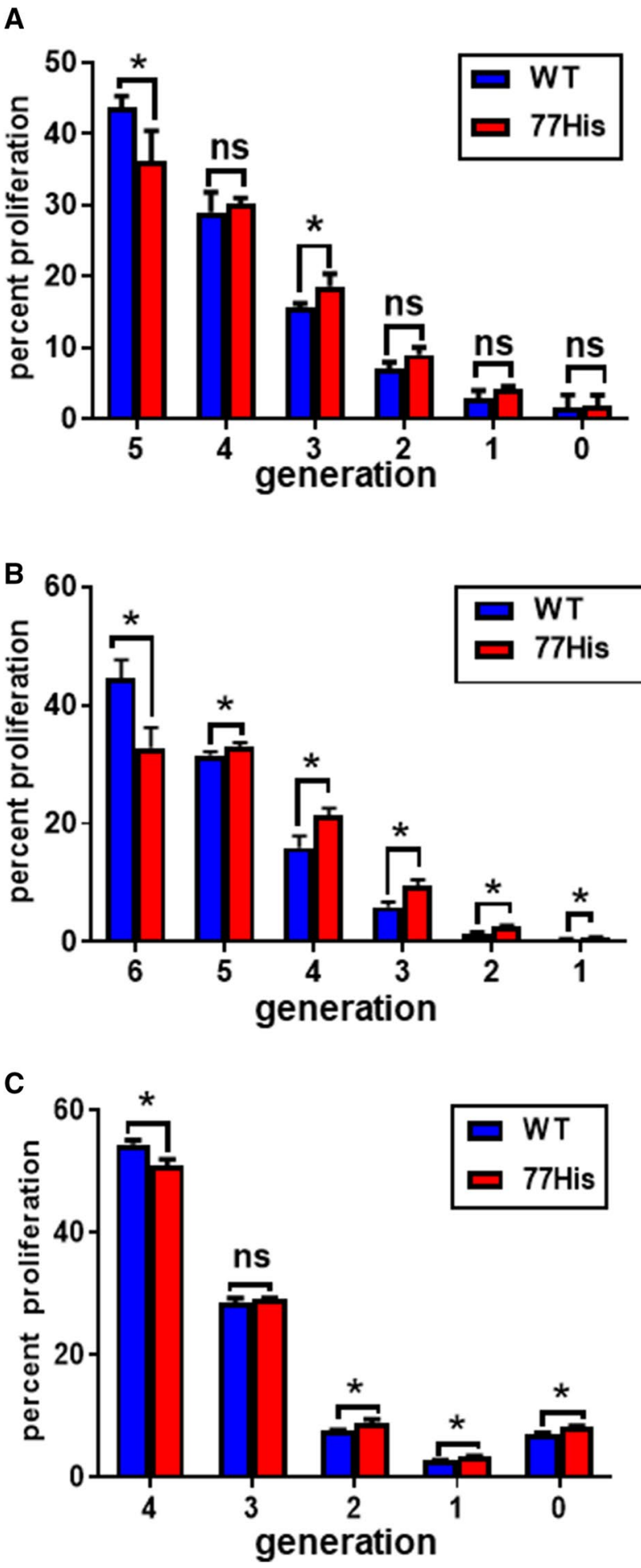

endogenous DCs per se, we isolated primary splenic DCs from untreated 77His and WT mice and used them as APCs in co-culture experiments (Fig. 6b). Co-cultures (splenic DCs plus CFSE-labeled $\mathrm{CD} 4{ }^{+} \mathrm{CD} 45.1^{+} \mathrm{CFSE}^{+}$OT-II T cells) were provided with $1.0 \mu \mathrm{M} \mathrm{OVA}_{323-339}$ peptide and $\mathrm{T}$ cell proliferation was assessed after $120 \mathrm{~h}$. We found significant decreases in the percentage of OT-II T cells that had 
undergone six cell divisions in 77His co-cultures compared to WT. A corresponding increase in the percentage of T cells was also observed at generations $1-5$ in $77 \mathrm{His}$ co-cultures. We next investigated 77His and WT primary splenic DCs for their ability to promote antigen-specific $\mathrm{T}$ cell proliferation at a second time point ( $72 \mathrm{~h}$ of co-culture) (Fig. 6c). We observed a significant decrease in the proportion of OT-II T cells that had undergone 4 cell divisions in the presence of 77His DCs compared to WT. In addition, we saw a corresponding increase in the proportion of $\mathrm{T}$ cells that underwent 2 or fewer divisions in 77 His co-cultures.

To further confirm these findings we next analyzed 77His BMDCs for their ability to promote antigen-specific T cell proliferation. LPS-stimulated 77His and WT BMDCs were incubated with varying concentrations of the OVA peptide for $24 \mathrm{~h}$ and then co-cultured with CFSE-labeled $\mathrm{CD} 4{ }^{+} \mathrm{CD} 45.1^{+}$OT-II T cells for $72 \mathrm{~h}$ (see "Materials and Methods"). In these assays too we observed an antigen concentration-dependent reduction in the number of proliferating $\mathrm{T}$ cells in co-cultures using 77His versus WT BMDCs (Fig. 7). The combined results show that the solitary 77His substitution in the CD11b protein is sufficient to compromise the ability of APCs in general, and DCs in particular, to promote antigen-dependent $\mathrm{T}$ cell proliferation in vivo and ex vivo.

One possible mechanism by which 77 His leads to reduced T cell proliferation may involve altered expression of costimulatory molecules on DCs. Previously, ligation of Mac-1 has been shown to lead to elevated expression of MHC-II, CD86, and CD40 on DCs (Behrens et al. 2007). Thus, we next analyzed splenic DCs (defined as CD11 $\mathrm{c}^{+}$cells) isolated from 77His and WT mice for the expression of MHC class II, CD40, CD80, and CD86. Expression of these markers was examined under both baseline conditions and after treatment with $1 \mu \mathrm{g} / \mathrm{mL}$ LPS for $24 \mathrm{~h}$. We observed no significant differences in expression of MHC class II or any of these costimulatory molecules either at baseline or after LPS treatment (Fig. 8). Splenic CD11 $\mathrm{c}^{+} \mathrm{CD} 11 \mathrm{~b}^{+}$cells were also interrogated for expression of the same markers, but once again, no significant difference was identified between genotypes (data not shown).

\section{Discussion}

Genetic variants in many adhesion molecule genes have been shown to be highly associated with different inflammatory diseases (Anbarasan et al. 2015; de Lange et al. 2017; Raman et al. 2013). A significant challenge is deciphering whether any of these variants affect the expression, function, or activity of the encoded proteins and, if so, how that might contribute to increased disease susceptibility or severity of the associated diseases. GWAS have strongly
A
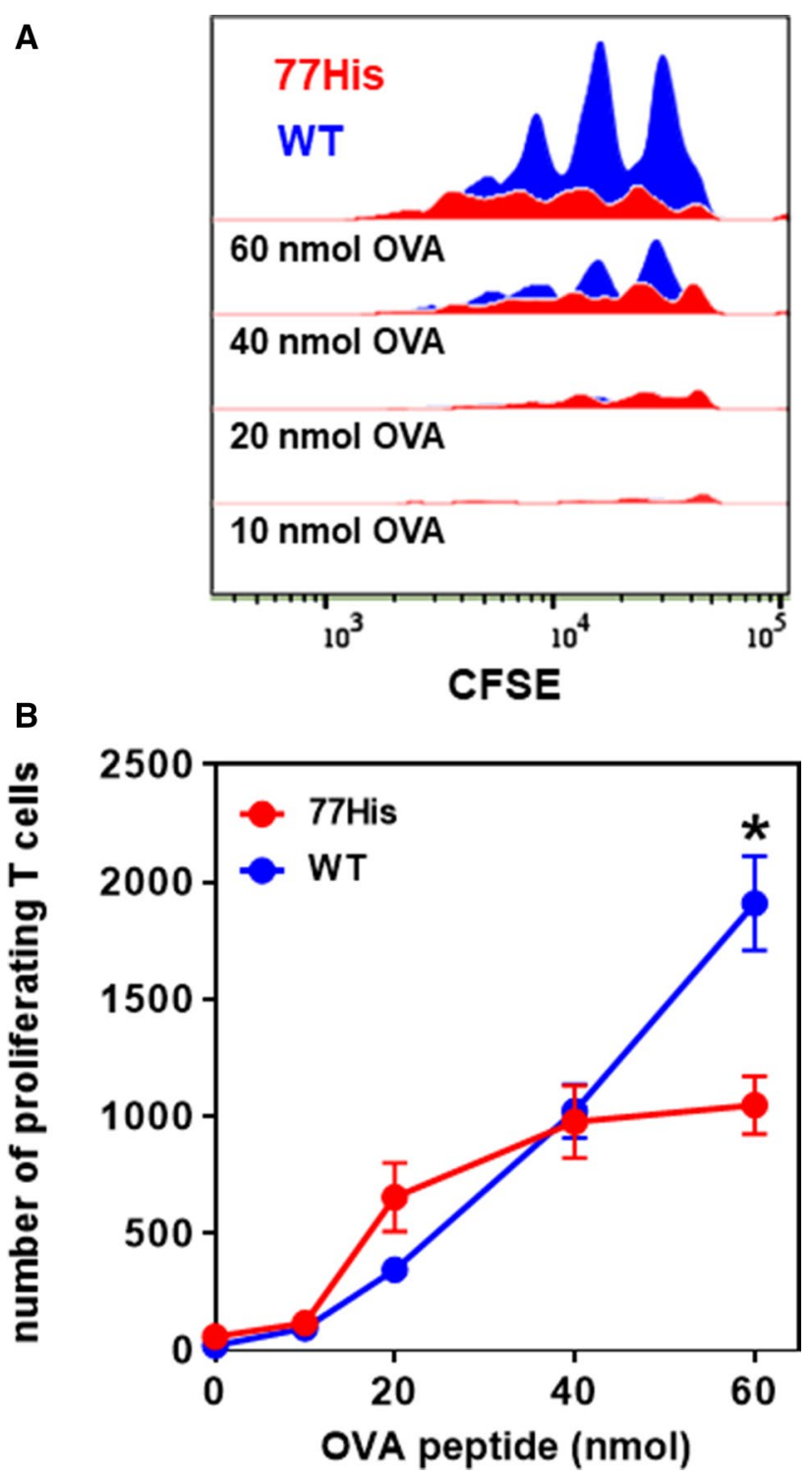

Fig. 7 Bone marrow-derived DCs (BMDCs) from 77His mice show impaired capacity to promote antigen-specific $\mathrm{T}$ cell proliferation. BMDCs generated from wild-type (WT) or 77His mice were used in co-culture assays to assess their capacity to support antigen-specific proliferation of OT-II cells. a Representative CFSE dilution histograms for proliferating $\mathrm{CD} 4^{+} \mathrm{T}$ cells in co-cultures using WT 77 His DCs in the presence of increasing amounts of OVA peptide. DCs were incubated with the indicated dose of OVA peptide for $24 \mathrm{~h}$, rinsed, and co-cultured with $\mathrm{CFSE}^{+} \mathrm{CD}^{+} \mathrm{T}$ cells. After $72 \mathrm{~h}$ of co-culture, $\mathrm{T}$ cell proliferation was assessed by flow cytometry (CFSE diminution). Note that the proliferation of $\mathrm{T}$ cells is reduced in the presence of 77His compared to WT BMDCs. b Pooled results (mean \pm SEM for $N=2$ biological replicates with three technical replicates per dose of OVA) from experiments performed as in panel A. One-way ANOVA with post hoc Tukey's multiple comparisons tests; the asterisk indicates $p<0.0001$ for WT versus 77His at the indicated dose 
Fig. 8 No impact of 77His on splenic DC expression of MHC class II and costimulatory molecules. Splenic DCs $\left(\mathrm{CD} 11 \mathrm{c}^{+}\right.$cells) from $77 \mathrm{His}$ $(N=4)$ and WT $(N=3)$ mice were treated with $1 \mu \mathrm{g} / \mathrm{mL}$ LPS (serotype 055:B5) for $24 \mathrm{~h}$ or left untreated. The results are displayed as the fold increase in the expression of MHC class II, CD40, CD80, and CD86 (LPS/ untreated)
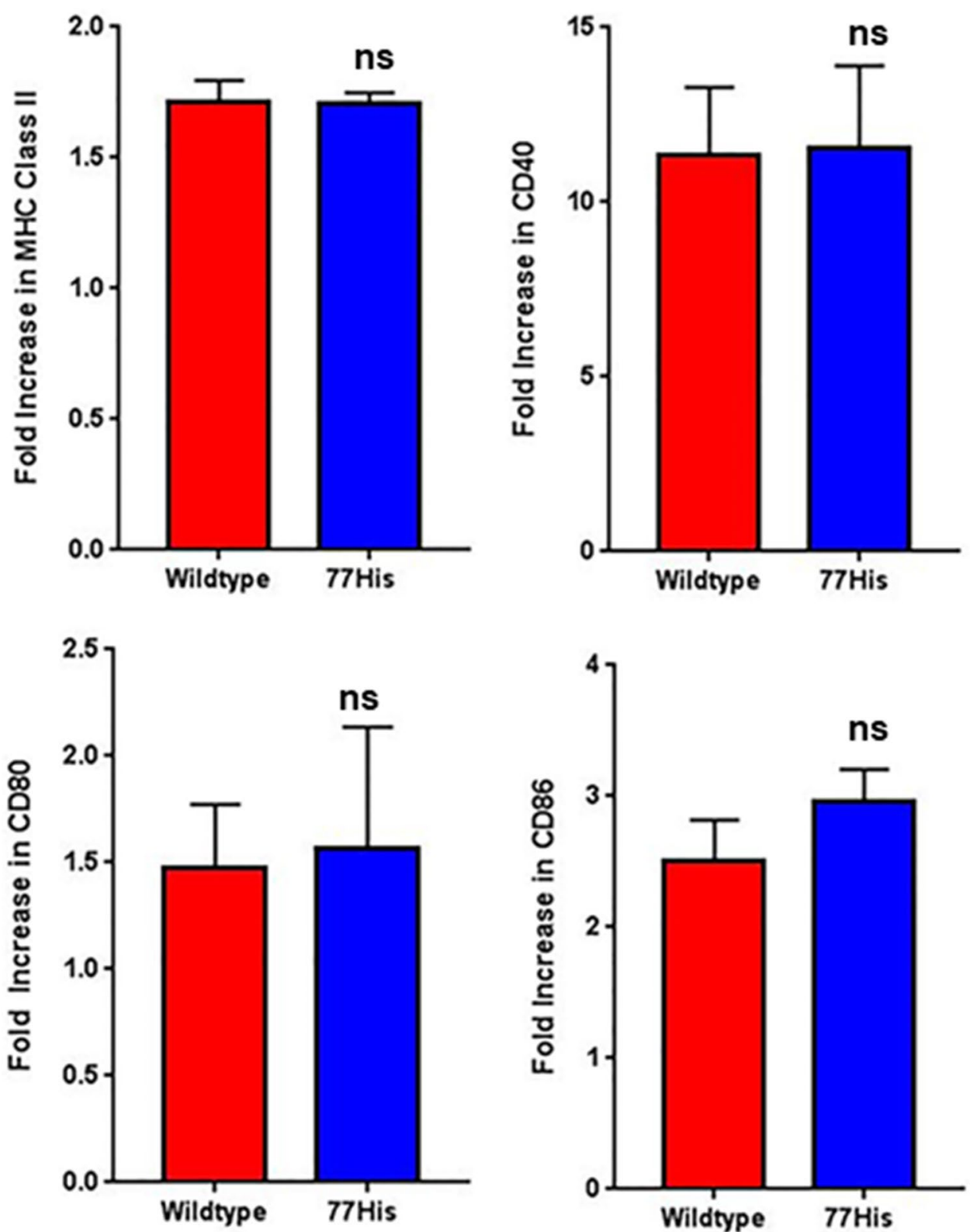

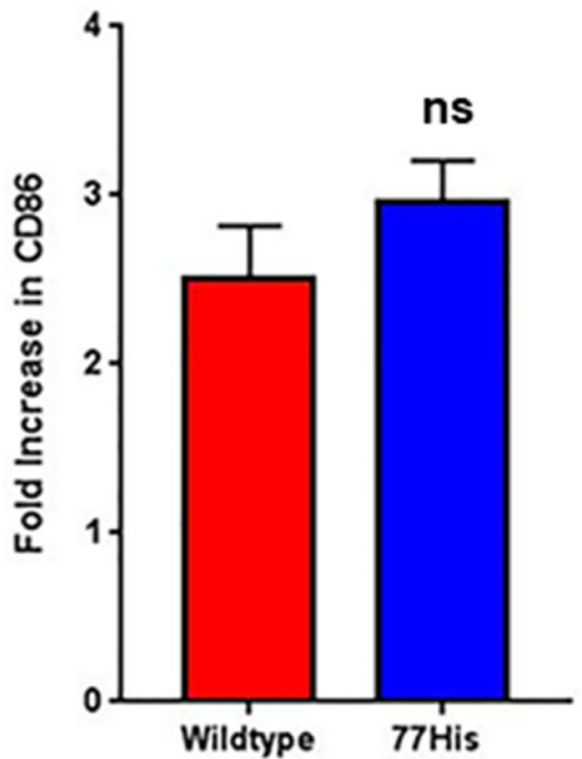

implicated the SNP rs1143679 in the ITGAM gene, which results in an arginine to histidine change at position 77 in the extracellular domain of CD11b, with the risk of SLE, systemic sclerosis, and certain cancers (Anaya et al. 2012; Hom et al. 2008; Lenci et al. 2012; Nath et al. 2008). Functional genomic studies of transfected cell lines and primary human leukocytes have shown that the expression of 77His inhibits cell adhesion to substrates, their phagocytic capacity, and their cytokine regulation (Fossati-Jimack et al. 2013; Reed et al. 2013; Rhodes et al. 2012; Rosetti et al. 2015; Zhou et al. 2013). However, these model systems are all in vitro ones and thereby are unable to assess the effect $77 \mathrm{His}$ might have on the initiation and progression of immune and inflammatory processes. Further complicating the interpretation of the in vitro studies is the presence of additional ITGAM SNPs in high LD with rs1143679. For example, the variant allele for rs1143678, which encodes a serine at position 1146 in $\mathrm{CD} 11 \mathrm{~b}$, has previously been shown to result in similar Mac-1-mediated defects in adhesion and phagocytosis to those reported for leukocytes expressing the 77 His variant (Zhou et al. 2013). In many previous studies of 77 His leukocytes, the presence/absence of 1146 Ser was not specifically ascertained. Consequently, the alterations of cell functions observed in these in vitro investigations cannot be attributed to 77 His per se with full confidence.

To sidestep these weaknesses, we report herein the generation of mice expressing a CD11b protein encoding histidine at amino acid position 77 , thus mimicking the human 
rs1143679 SNP variant. Granted mice are not humans, but despite this obvious drawback genetically engineered mice have been a powerful and useful tool for addressing phenotypic changes resulting from genetic alterations present in the human genome (Ernst 2016). In this study 77His mice were found to be viable and fertile with no obvious spontaneous phenotypes, and no difference in Mac-1 expression was observed on different leukocyte subsets from $77 \mathrm{His}$ mice compared to WT. We did not observe any significant effects of the 77His variant on outcomes in two different models of localized inflammation (peritonitis and the dermal Shwartzman reaction), even though previous studies of CD11b null mutant mice have revealed an important contribution of Mac-1 to leukocyte recruitment and the resultant tissue damage (Hirahashi et al. 2006; Jawhara et al. 2017). This suggests that the single 77His amino acid change is not sufficient to alter these underlying Mac-1-dependent processes in vivo, underscoring that the biology of the 77 His variant is not necessarily the same as that of the null mutation.

It is possible that the 77His variant does affect Mac-1's ability to promote leukocyte recruitment and activation in vivo, but this effect is masked due to redundancies in function with other adhesion molecules like LFA-1 (Ding et al. 1999). In addition, it is possible that the 77 His variant per se may not specifically modify these inflammatory processes, but other ITGAM SNPS may play a role. As discussed above, rs 1143678 is in high LD with rs 1143679 and the amino acid change resulting from this SNP has been shown to decrease both neutrophil adhesion to purified ICAM- 1 and firm adhesion to stimulated endothelial cells in vitro. The development of additional lines of Itgam SNP variant mice will be needed to determine the impact of other CD11b amino acid substitutions on Mac-1-dependent functions.

Mac-1 expression on certain DC subsets has been shown to regulate T cell proliferation (Bai et al. 2012; Behrens et al. 2007; Ling et al. 2014; Varga et al. 2007). For example, Ling et al. (2014) previously showed that this integrin is important in LPS-induced signaling by myeloid DCs and that loss of its expression by splenic DCs can reduce T cell proliferation in co-cultures. In the studies reported here, donor OT-II T cells administered to 77His recipients injected with OVA showed a significant reduction in proliferation when compared to OT-II T cells recovered from similarly treated WT mice. We also observed significantly diminished OT-II $\mathrm{T}$ cell proliferation in response to OVA peptide in co-culture experiments using 77His splenic DCs or BMDCs. This outcome was also observed for co-cultures using CD11b null mutant splenic DCs (data not shown). This suggests that in vivo the 77His variant is sufficient to compromise the ability of Mac-1 on DCs (and possibly other APCs) to promote antigen-specific $\mathrm{T}$ cell proliferation. Previous in vitro studies using cultured murine bone marrow-derived
DCs (BMDCs) showed Mac-1-mediated inhibition of APC functions (Behrens et al. 2007; Ling et al. 2014; Varga et al. 2007), so we tested if the 77His variant also compromises the ability of LPS-stimulated BMDCs to restrict proliferation of $\mathrm{T}$ cells in the presence of anti-CD3 and anti-CD28 antibodies. BMDCs generated from 77His and WT mice expressed CD11b equally, and after maturation in response to LPS expressed equal amounts MHC-II (data not shown). In contrast to the results of our antigen-specific $\mathrm{T}$ cell proliferation experiments, the $77 \mathrm{His}$ variant did not significantly alter proliferation of $\mathrm{CD} 3 / \mathrm{CD} 28$-stimulated $\mathrm{CD} 4^{+} \mathrm{T}$ cells in co-culture assays with BMDCs (data not shown).

At this time, the mechanism by which this single amino acid substitution in murine CD11b leads to impaired antigen-specific $\mathrm{T}$ cell proliferation has not been identified. However this effect was not associated with diminished expression of MHC-II and costimulatory molecules by DCs, as was previously shown for cultured DCs from CD11b null mutant mice (Ling et al. 2014). It is possible that 77 His compromises the ability of DCs to interact with one or more Mac-1 ligands, thereby altering DC intracellular signaling pathways and downstream expression of cytokines and chemokines involved in regulating $\mathrm{T}$ cell proliferation in vitro (Bai et al. 2012; Ling et al. 2014). Further investigations of the effects of the 77His variant on Mac-1-dependent inside-out and outside-in signaling pathways and cytokine expression in DCs are thus needed to determine whether they contribute mechanistically to the reduced $\mathrm{T}$ cell proliferation phenotype observed in these studies.

In summary, by substituting a proline at position 77 in the mouse CD11b protein with a histidine, we have developed and characterized a new line of mice expressing the human SNP rs1143679 variant allele. In two different acute inflammation models we detected no significant differences in leukocyte recruitment or tissue damage in 77His mice compared to WT, but we did observe (both in vivo and in vitro) that this variant inhibited the ability of APCs to promote antigen-specific $\mathrm{T}$ cell proliferation. Additional experiments using the $77 \mathrm{His}$ variant mice in other immune and inflammatory models are ongoing, and the results of those experiments will help determine the full impact of this solitary amino acid change in CD11b on Mac-1-dependent processes in vivo. Ultimately, it will be very informative to investigate whether 77His alters the development or progression of autoimmunity, which can be done by using various induced inflammatory disease models or by breeding 77His mice with SLE-prone strains of mice.

Acknowledgements The authors gratefully acknowledge the help of Dr. Robert Kesterson and the UAB Transgenic \& Genetically Engineered Model Systems Core Facility (supported by NIH Grants P30 CA13148, P30 AR018311. P30 DK074038, and P30 DK079626), the UAB Heflin Center for Genomic Science Core Laboratories (supported by the NIH Grant P30 CA013148), and the UAB Comprehensive Flow 
Cytometry Core (supported by NIH Grants P30 AR048311 and P30 AI27667), as well as the UAB Animal Resources Program Comparative Pathology Laboratory for their histology services. We would also like to thank Dr. Andy Gibson for his help with genotyping the 77His variant mice.

Author contributions JTA is a primary author involved in the design, conception, and completion of all of the studies presented in the manuscript. RVJ was involved with DC cell culture and T cell proliferation experiments. JLB was involved with the BMDC:T cell proliferation experiments. TTW was involved with DC cell culture and analysis of costimulatory marker expression. BL was involved in T cell proliferation conception and design. TRS was involved in histological analysis. AJS was involved in study conception and design. DCB was the principal investigator, corresponding author, involved in study conception and design.

Funding This work was supported by the National Institutes of Health Grants 1R21AR069295 and 1R01DK099092, and by an UAB AMC 21 pilot Grant.

\section{Compliance with ethical standards}

Conflict of interest The authors declare that the research presented was conducted in the absence of any commercial or financial relationships that could be construed as a potential conflict of interest.

Ethical approval All applicable international, national, and/or institutional guidelines for the care and use of animals were followed. All animal procedures including euthanasia were approved by The University of Alabama at Birmingham Institutional Animal Care and Use Committee.

Research involving human and animal participants This article does not contain any studies with human participants.

Open Access This article is distributed under the terms of the Creative Commons Attribution 4.0 International License (http://creativeco mmons.org/licenses/by/4.0/), which permits unrestricted use, distribution, and reproduction in any medium, provided you give appropriate credit to the original author(s) and the source, provide a link to the Creative Commons license, and indicate if changes were made.

\section{References}

Anaya JM et al (2012) Evaluation of genetic association between an ITGAM non-synonymous SNP (rs1143679) and multiple autoimmune diseases. Autoimmun Rev 11:276-280. https:// doi.org/10.1016/j.autrev.2011.07.007

Anbarasan C, Bavanilatha M, Latchumanadhas K, Ajit Mullasari S (2015) ICAM-1 molecular mechanism and genome wide SNP's association studies. Indian Heart J 67:282-287. https:// doi.org/10.1016/j.ihj.2015.03.005

Bai Y et al (2012) Integrin CD11b negatively regulates TLR9-triggered dendritic cell cross-priming by upregulating microRNA146a. J Immunol 188:5293-5302. https://doi.org/10.4049/ jimmunol.1102371

Barnden MJ, Allison J, Heath WR, Carbone FR (1998) Defective TCR expression in transgenic mice constructed using cDNA-based alpha- and beta-chain genes under the control of heterologous regulatory elements. Immunol Cell Biol 76:34-40. https://doi.org/10.1046/j.1440-1711.1998.00709.x

Behrens EM, Sriram U, Shivers DK, Gallucci M, Ma Z, Finkel TH, Gallucci S (2007) Complement receptor 3 ligation of dendritic cells suppresses their stimulatory capacity. J Immunol 178:6268-6279

Bullard DC, Hu X, Schoeb TR, Axtell RC, Raman C, Barnum SR (2005) Critical requirement of CD11b (Mac-1) on T cells and accessory cells for development of experimental autoimmune encephalomyelitis. J Immunol 175:6327-6333

Chen J et al (2008) The role of CD11b in phagocytosis and dendritic cell development. Immunol Lett 120:42-48. https://doi. org/10.1016/j.imlet.2008.06.010

Coxon A et al (1996) A novel role for the beta 2 integrin CD11b/CD18 in neutrophil apoptosis: a homeostatic mechanism in inflammation. Immunity 5:653-666

de Lange KM et al (2017) Genome-wide association study implicates immune activation of multiple integrin genes in inflammatory bowel disease. Nat Genet 49:256-261. https://doi.org/10.1038/ ng. 3760

Ding ZM et al (1999) Relative contribution of LFA-1 and Mac-1 to neutrophil adhesion and migration. J Immunol 163:5029-5038

Dirk Nolte RH, Schmid Petra, Botzlar Andreas, Menger Michael D, Neumueller Christine, Sinowatz Fred, Vestweber Dietmar, Messmer Konrad (1994) Role of Mac-1 and ICAM-1 in ischemia-reperfusion injury in a microcirculation model of BALB/C mice. Am J Physiol 267:1320-1328

Ehirchiou D, Xiong Y, Xu G, Chen W, Shi Y, Zhang L (2007) CD11b facilitates the development of peripheral tolerance by suppressing Th17 differentiation. J Exp Med 204:1519-1524. https://doi. org/10.1084/jem.20062292

Ernst W (2016) Humanized mice in infectious diseases. Comp Immunol Microbiol Infect Dis 49:29-38. https://doi.org/10.1016/j.cimid .2016.08.006

Fagerholm SC, MacPherson M, James MJ, Sevier-Guy C, Lau CS (2013) The CD11b-integrin (ITGAM) and systemic lupus erythematosus. Lupus 22:657-663. https://doi.org/10.1177/09612 03313491851

Fossati-Jimack L et al (2013) Phagocytosis is the main CR3-mediated function affected by the lupus-associated variant of $\mathrm{CD} 11 \mathrm{~b}$ in human myeloid cells. PLoS One 8:e57082. https://doi. org/10.1371/journal.pone.0057082

Han C, Jin J, Xu S, Liu H, Li N, Cao X (2010) Integrin CD11b negatively regulates TLR-triggered inflammatory responses by activating Syk and promoting degradation of MyD88 and TRIF via Cbl-b. Nat Immunol 11:734-742. https://doi.org/10.1038/ni.1908

Herter J, Zarbock A (2013) Integrin regulation during leukocyte recruitment. J Immunol 190:4451-4457. https://doi.org/10.4049/ jimmunol.1203179

Hirahashi J et al (2006) Mac-1 signaling via Src-family and Syk kinases results in elastase-dependent thrombohemorrhagic vasculopathy. Immunity 25:271-283. https://doi.org/10.1016/j.immun i.2006.05.014

Hom $\mathrm{G}$ et al (2008) Association of systemic lupus erythematosus with C8orf13-BLK and ITGAM-ITGAX. N Engl J Med 358:900-909. https://doi.org/10.1056/NEJMoa0707865

Jawhara S, Pluskota E, Cao W, Plow EF, Soloviev DA (2017) Distinct Effects of Integrins alphaXbeta2 and alphaMbeta2 on Leukocyte Subpopulations during Inflammation and Antimicrobial Responses. Infect Immun 85:e00644. https://doi.org/10.1128/ IAI.00644-16

Jimenez RV, Wright TT, Jones NR, Wu J, Gibson AW, Szalai AJ (2018) C-Reactive protein impairs dendritic cell development, maturation, and function: implications for peripheral tolerance. Front Immunol 9:372. https://doi.org/10.3389/fimmu.2018.00372 
Kevil CG et al (2004) Loss of LFA-1, but not Mac-1, protects MRL/ MpJ-Fas(lpr) mice from autoimmune disease. Am J Pathol 165:609-616. https://doi.org/10.1016/S0002-9440(10)63325-1

Lenci RE et al (2012) Integrin genes and susceptibility to human melanoma. Mutagenesis 27:367-373. https://doi.org/10.1093/mutag e/ger090

Leon F et al (2006) Antibodies to complement receptor 3 treat established inflammation in murine models of colitis and a novel model of psoriasiform dermatitis. J Immunol 177:6974-6982

Lim J, Hotchin NA (2012) Signalling mechanisms of the leukocyte integrin alphaMbeta2: current and future perspectives. Biol Cell 104:631-640. https://doi.org/10.1111/boc.201200013

Ling GS et al (2014) Integrin CD11b positively regulates TLR4induced signalling pathways in dendritic cells but not in macrophages. Nat Commun 5:3039. https://doi.org/10.1038/ncomm s4039

Lu H et al (1997) LFA-1 is sufficient in mediating neutrophil emigration in Mac-1-deficient mice. J Clin Invest 99:1340-1350. https ://doi.org/10.1172/JCI119293

MacPherson M, Lek HS, Prescott A, Fagerholm SC (2011) A systemic lupus erythematosus-associated $\mathrm{R} 77 \mathrm{H}$ substitution in the $\mathrm{CD} 11 \mathrm{~b}$ chain of the Mac-1 integrin compromises leukocyte adhesion and phagocytosis. J Biol Chem 286:17303-17310. https://doi. org/10.1074/jbc.M110.182998

Maiti AK et al (2014) Combined protein- and nucleic acid-level effects of rs1143679 (R77H), a lupus-predisposing variant within ITGAM. Hum Mol Genet 23:4161-4176. https://doi.org/10.1093/ hmg/ddu106

Monrad S, Kaplan MJ (2007) Dendritic cells and the immunopathogenesis of systemic lupus erythematosus. Immunol Res 37:135-145

Mulligan MS, Lentsch AB, Miyasaka M, Ward PA (1998) Cytokine and adhesion molecule requirements for neutrophil recruitment during glycogen-induced peritonitis. Inflamm Res 47:251-255. https://doi.org/10.1007/s000110050326

Nath SK et al (2008) A nonsynonymous functional variant in integrinalpha(M) (encoded by ITGAM) is associated with systemic lupus erythematosus. Nat Genet 40:152-154. https://doi.org/10.1038/ ng.71

Raman K et al (2013) Genetic markers of inflammation and their role in cardiovascular disease. Can J Cardiol 29:67-74. https://doi. org/10.1016/j.cjca.2012.06.025

Reed JH et al (2013) Complement receptor 3 influences toll-like receptor 7/8-dependent inflammation: implications for autoimmune diseases characterized by antibody reactivity to ribonucleoproteins. J Biol Chem 288:9077-9083. https://doi.org/10.1074/jbc. M112.403303

Ren B et al (2004) The virulence function of Streptococcus pneumoniae surface protein A involves inhibition of complement activation and impairment of complement receptor-mediated protection. J Immunol 173:7506-7512

Rhodes B, Furnrohr BG, Roberts AL, Tzircotis G, Schett G, Spector TD, Vyse TJ (2012) The rs1143679 (R77H) lupus associated variant of ITGAM (CD11b) impairs complement receptor 3 mediated functions in human monocytes. Ann Rheum Dis 71:2028-2034. https://doi.org/10.1136/annrheumdis-2012-201390

Rosetti F et al (2012) Human lupus serum induces neutrophil-mediated organ damage in mice that is enabled by mac-1 deficiency. J Immunol 189:3714-3723. https://doi.org/10.4049/jimmu nol.1201594
Rosetti F et al (2015) A lupus-associated Mac-1 variant has defects in integrin allostery and interaction with ligands under force. Cell Rep 10:1655-1664. https://doi.org/10.1016/j.celrep.2015.02.037

Rosetti F, Mayadas TN (2016) The many faces of Mac-1 in autoimmune disease. Immunol Rev 269:175-193. https://doi. org/10.1111/imr.12373

Rothstein JL, Schreiber H (1988) Synergy between tumor necrosis factor and bacterial products causes hemorrhagic necrosis and lethal shock in normal mice. Proc Natl Acad Sci USA 85:607-611

Sandor N, Kristof K, Parej K, Pap D, Erdei A, Bajtay Z (2013) CR3 is the dominant phagocytotic complement receptor on human dendritic cells. Immunobiology 218:652-663. https://doi. org/10.1016/j.imbio.2012.07.031

Schmidt J, Klempp C, Buchler MW, Marten A (2006) Release of iC3b from apoptotic tumor cells induces tolerance by binding to immature dendritic cells in vitro and in vivo. Cancer Immunol Immunother 55:31-38

Skoberne M, Somersan S, Almodovar W, Truong T, Petrova K, Henson PM, Bhardwaj N (2006) The apoptotic-cell receptor CR3, but not alphavbeta5, is a regulator of human dendritic-cell immunostimulatory function. Blood 108:947-955

Soloviev DA, Jawhara S, Fonzi WA (2011) Regulation of innate immune response to Candida albicans infections by alphaMbeta2-Pra1p interaction. Infect Immun 79:1546-1558. https:// doi.org/10.1128/IAI.00650-10

Stevanin M et al (2017) CD11b regulates the Treg/Th17 balance in murine arthritis via IL-6. Eur J Immunol 47:637-645. https://doi. org/10.1002/eji.201646565

Tan SM (2012) The leucocyte beta2 (CD18) integrins: the structure, functional regulation and signalling properties. Biosci Rep 32:241-269. https://doi.org/10.1042/BSR20110101

Tomasz Liberek MC, Lichodziejewska-Niemierko Monika, Krzysztof Lewandowski ABR (2004) Transmigration of blood leukocytes into the peritoneal cavity is related to the upregulation of ICAM-1 (CD54) and Mac-1 (CD11b/CD18) adhesion molecules. Perit Dial Int 24:139-146

Varga G et al (2007) Active MAC-1 (CD11b/CD18) on DCs inhibits full T-cell activation. Blood 109:661-669. https://doi.org/10.1182/ blood-2005-12-023044

Yang J, Roy A, Zhang Y (2013a) BioLiP: a semi-manually curated database for biologically relevant ligand-protein interactions. Nucleic Acids Res 41:D1096-D1103. https://doi.org/10.1093/ nar/gks966

Yang J, Roy A, Zhang Y (2013b) Protein-ligand binding site recognition using complementary binding-specific substructure comparison and sequence profile alignment. Bioinformatics 29:25882595. https://doi.org/10.1093/bioinformatics/btt447

Zhou Y et al (2013) Multiple lupus-associated ITGAM variants alter Mac-1 functions on neutrophils. Arthritis Rheum 65:2907-2916. https://doi.org/10.1002/art.38117

Publisher's Note Springer Nature remains neutral with regard to jurisdictional claims in published maps and institutional affiliations. 